\title{
013 PP AN 'ENRICHED LANDSCAPE' OF QUALITATIVE RESEARCH: DIFFERENT APPROACHES TO THREE PUBLIC HEALTH ISSUES
}

D Romero. Hunter College and the Graduate Center, City University of New York, School of Public Health, New York, USA

\subsection{6/bmjopen-2015-UCLSymposiumAbstracts.24}

Qualitative methods have much to contribute to public health research. Below are three public health projects that provide a sampling of empirical research for reflection on the varied use of qualitative methods.

Collaborative Community Health Assessment St. Vincent's Hospital closed in 2010, resulting in loss of an ER, in-patient facilities, a trauma center, and outpatient clinics. There was great concern about potential gaps in health care. Romero et al worked with community partners, elected officials, health and social services providers, residents and others to collect data to assess the impact of the hospital closure, via focus groups, keyinformant interviews and a community survey.

L-GEAR Project US rates of adolescent pregnancy are high among industrialized countries. There is a dearth of qualitative data from adolescents regarding life experiences, educational and career goals, and how their parents' own experiences might influence teens' attitudes and sexual behaviors. We are conducting in-depth interviews (IDIs) with adolescent girls, boys and their parents about their current life circumstances and future goals, and how sexual and childbearing behaviors factor into their lives.

Welfare Policy Analysis US welfare reform in the 1990s included state "child-exclusion" policies prohibiting additional cash assistance to families with a newborn. We conducted several studies to analyze the policy involving (1) IDIs of women subject to the policy; (2) review of effectiveness evaluations and content analysis vis-à-vis human rights treaties; (3) key-informant interviews with state welfare directors.

These three projects illustrate the wide range of qualitative research methods available to public health and other researchers, including in-depth and key-informant interviews, focus groups, and content analysis. It is clear that their combined use, including quantitative methods such as surveys, have much to offer to provide a deeper understanding of public health issues and related social programs and policies. 